\title{
INPUT FREQUENCIES IN PROCESSING OF VERBAL MORPHOLOGY IN L1 AND L2: EVIDENCE FROM RUSSIAN
}

\author{
ELENA TKACHENKO AND TATIANA CHERNIGOVSKAYA \\ University of Oslo and St. Petersburg State University
}

\section{ABSTRACT}

In this study we take a usage-based perspective on the analysis of data from the acquisition of verbal morphology by Norwegian adult learners of L2 Russian, as compared to children acquiring Russian as an L1. According to the usage-based theories, language learning is input-driven and frequency of occurrence of grammatical structures and lexical items in the input plays a key role in this process. We have analysed to what extent the acquisition and processing of Russian verbal morphology by children and adult L2 learners is dependent on the input factors, in particular on type and token frequencies. Our analysis of the L2 input based on the written material used in the instruction shows a different distribution of frequencies as compared to the target language at large. The results of the tests that elicited present tense forms of verbs belonging to four different inflectional classes (-AJ-,-A-, -I-, and -OVA-) have demonstrated that for both Russian children and L2 learners type frequency appears to be an important factor, influencing both correct stem recognition and generalisations. The results have also demonstrated token frequency effects. For L2 learners we observed also effects of formal instruction and greater reliance on morphological cues. In spite of the fact that L2 learners did not match completely any of the child groups, there are many similarities between L1 and L2 morphological processing, the main one being the role of frequency.

\section{[1] INTRODUCTION}

Usage-based models view language learning as a process first and foremost relying on the general cognitive learning principles (Langacker 1987; Kemmer \& Barlow 2000; Langacker 2000; Bybee \& Hopper 2001; Tomasello 2003; Goldberg 2006). According to this view the linguistic knowledge is acquired in a bottom-up direction, so that actual language use shapes the nature of generalisations that emerge from the analysis of patterns occurring in the input: "The children are picking up frequent patterns from what they hear around them, and only slowly making more abstract generalisations as the database of related utterances grows" (Ellis 2003, 70). 
In recent years a handful of studies have employed usage-based theories to account for patterns of language processing in second language and bilingual acquisition (e.g. Ellis 1998; Gathercole 2007) (see also Ellis 2002; Robinson \& Ellis 2008 for a review). In this study we explore the data from the acquisition of verbal morphology by adult L2 learners of Russian, as compared to children acquiring it as an L1. Second language processing presents an interesting field of research because the input of L2 learners may potentially differ in many respects from the input that children are exposed to. In this paper we aim at investigating to what extent the acquisition and processing of Russian verbal morphology by children and adult L2 learners is dependent on the input.

\section{[1.1] Differences and similarities in the input to L1 and L2 learners}

One of the continuing issues in second language acquisition (SLA) research has for many years been whether L2 learners acquire/learn the language in the same way as children acquiring their first language (L1). The differences between L1 and L2 acquisition are evident in many domains: ultimate attainment, achieved fluency, accuracy and so forth (see e.g. Hyltenstam 1992; Hyltenstam \& Abrahamsson 2000; Singleton 2003). The sources of explanations for these differences are, however, somewhat differently shaped in different theoretical approaches: within the generative framework the discussion has focused mainly on the availability of the UG in L2 acquisition (White 1989; Eubank 1991; Schwartz 1992; Flynn 1996; White 2003); cognitive approaches to language acquisition view the process of learning a language as an instantiation of all other types of learning and for this reason try to explain these differences by a range of factors that might influence language processing, including variation in learning environments, adults' better developed analytical thinking, influence of the native language, as well as amount of input received and its properties. Another source of variation in L2 processing may lie in learner-internal factors such as motivation, aptitude, language analytic abilities, attitudes and so forth (Dörnyei \& Skehan 2002; Robinson 2002; Masgoret \& Gardner 2003; Dörnyei 2005).

Comparing the contexts of L1 and L2 acquisition, there are several points where these differ. The initial point when the process of acquisition starts differs enormously for the children acquiring their first language and adults beginning to learn an L2. When adults start learning a second language, they already possess first, a substantial knowledge of the world, and second, the knowledge of their L1 (Gass 1996); for children the language acquisition and conceptual and cognitive development proceed simultaneously. When children acquire the language, they gradually extract the grammatical forms from the input and build their grammatical system in a piecemeal fashion. Adult L2 learners, especially in a classroom context, can treat language as an object of learning in itself and as a consequence, can deal with the linguistic system structurally. Furthermore, 
L2 learners can be exposed to formal instruction and for them explicit rules can be formulated. Thus, while children acquire language implicitly, adult L2 learners have an opportunity for explicit learning (see a discussion on the interface between explicit and implicit learning in SLA in e.g. Ellis 1994; DeKeyser 1997; MacWhinney 1997; Ellis 2005). Views on the role of explicit grammar instruction in second language classrooms have been changing throughout many years of SLA research, and various teaching methods allot it different places and varying degrees of importance (Ellis 1990; Celce-Murcia 1991). Focus on form in the formal instruction to L2 learners is yet another point of difference between L1 and L2 acquisition: while children acquire morphology through communication, and their first focus of attention is meaning, L2 learners are to a lesser or greater extent (depending on the teaching method) focused on grammatical forms, even in communicative methods (Long 1991; Spada 1997; Doughty \& Williams 1998; Long \& Robinson 1998; Norris \& Ortega 2000, 2001). The last point we will mention here is the significant difference in the input for $\mathrm{L} 1$ and $\mathrm{L} 2$ learners. Children receive a lot of input, and this input is natural; while L2 learners' input can be very limited, and it is characterised by some specific features (Ellis 2003, 72), which we discuss later.

In this study we consider in detail two of the above mentioned differences: formal instruction and focus on form, and the nature of input in the L2 learning context. Later in this paper we will analyse in detail how the target morphological structures are presented to the L2 learners who participated in this study, what kind of instruction the learners received in the target forms, and what is their distribution in the L2 input, as compared to the target language (TL) input at large.

\section{[1.2] Past tense debate and L2 morphological processing}

Acquisition of verbal morphology has for many years been an issue of much debate within linguistic theory of acquisition, mental grammar representation and cognitive processing. Within the "nature vs. nurture" discussion, an issue concerning the acquisition of the English past tense has attracted much attention and this "past tense debate" continues (Marslen-Wilson \& Tyler 1998; Pinker 2001; McClelland \& Patterson 2002a,b; Pinker \& Ullman 2002; Marslen-Wilson \& Tyler 2005). The discussion centres on the question of whether the processing of regular and irregular morphological forms is driven by two distinct mechanisms (the Dual Mechanism Account), or by one single mechanism (the Single Mechanism Account). The proponents of the Dual Mechanism Account claim that regular forms are computed by a rule-processing system, while irregular morphological forms are processed in associative memory (Pinker \& Prince 1988; Marcus et al. 1992; Prasada \& Pinker 1993; Marcus 1995; Marcus et al. 1995; Clahsen 1997; Ullman 1997; Pinker 1999; Ullman 1999; Pinker 2001; Ullman 2001b,a; Pinker \& Ullman 2002; Clahsen 2006; Clahsen \& Felser 2006b). The opposite view claims that both 
regular and irregular forms are processed by one single mechanism in associative memory (Bybee \& Slobin 1982; Rumelhart \& McClelland 1986; Langacker 1987; MacWhinney \& Leinbach 1991; Plunkett \& Marchman 1991, 1993; Bybee 1995; Plunkett \& Marchman 1996; Langacker 2000; Bybee \& Hopper 2001; Eddington 2002). The major point of disagreement between these competing accounts lies in their predictions regarding the role of input factors in processing of inflectional morphology: whereas the Dual Mechanism Account predicts that frequency factors influence the acquisition and processing of irregular forms, but not regular ones; according to the Single Mechanism Account, processing of all types of inflectional forms, both regular and irregular, depends heavily on input frequencies.

The proponents of the Dual Mechanism Account have lately extended their theories and formulated two different accounts of morphological processing in L2 acquisition. One such model was worked out by Clahsen and his colleagues. According to the Shallow Structure Hypothesis ( $\mathrm{SSH}$ ) formulated recently (Clahsen \& Felser 2006b,a), the L2 grammatical processing is different from that of L1 particularly in the area of syntax, while morphological processing in L1 and L2 does not differ and shows a dissociation of rule-based and associative patterning. They advocate this view based on their findings in a study on morphological processing of German participle inflection by native speakers and L2 learners (Hahne et al. 2006). The results of this study have demonstrated that the L2 learners showed different ERP responses to violations of regular and irregular inflection, and their responses were similar to that of the native speakers. The conclusion made was that in L2 and in L1 different processes are involved in regular and irregular inflection. However, this study also included a second ERP experiment on the processing of German noun plurals, and for nouns the findings were different: while the L2 learners performed similarly to native speakers for participles, they showed different patterns for noun plurals. The explanation provided was that the L2 learners' processing of participles was more automatised than their processing of noun plurals due to the fact that German noun plural system is rather unusual with a low frequency regular default and more diverse in inflections and, thus, more difficult for L2 learners to acquire. Consequently, the overall results of this study cannot in full support the hypothesis by Clahsen and his colleagues that L2 morphological processing does not differ from L1 morphological processing. This idea was also criticised in a commentary by Ullman (2006), who pointed out several important differences between the SSH and his own model and argued that most of the data can be explained by the declarative/procedural model (Ullman 1997, 2001a,b,c, 2004).

The declarative/procedural model (DPM) proposed by Ullman was initially worked out for L1 morphological processing. The core assumption of this model is that different aspects of linguistic processing are linked to different brain memory systems. The declarative memory system subserves the associative, lexical- 
based processing, whereas the procedural memory subserves the grammatical, rule-based processing. In the same way as other dual-mechanism models, the declarative/procedural model makes specific assumptions with regard to the dissociation of morphological processing of regular and irregular forms: regular forms are processed in the procedural memory, while irregular forms - in the declarative memory. However, for the L2 morphological processing, Ullman hypothesises that "processing of linguistic forms that are computed grammatically by procedural memory in $\mathrm{L} 1$ is expected to be dependent to a greater extent upon declarative memory in L2" (Ullman 2001c, 109). Thus, morphological processing in L2 is seen as different from that in L1. Since the lexicon/grammar dissociations posited for $\mathrm{L} 1$ can be weaker or even absent in L2, it is predicted that both regular and irregular forms can be computed and processed by the associative memory in L2, and frequency effects can be expected for both regular and irregular forms. This particular point is similar to the predictions made by the usage-based models that also expect that all morphological forms will be influenced by frequency of occurrence.

The usage-based theories view frequency as an important factor in language learning. As Ellis put it, "language processing is intimately tuned to input frequency" (Ellis 2002, 143). This principle holds for L1 and L2 processing, and Ellis claims that "the L1 acquisition sequence - from formulas, through low-scope patterns, to constructions - could serve well as a reasonable default in guiding the investigation of the ways in which exemplars and their type and token frequencies determine the second language acquisition of structure" (Ellis 2002, 170).

TYPE FREQUENCY refers "to the frequency of occurrence of a linguistic pattern, or in other words, to the size of a certain class of words using this pattern" (Gor 2007, 371). TOKEN FREQUENCY, on the other hand, shows "how often a language user encounters a certain word, either by producing it or hearing it produced by other speakers" (Gor 2007, 371). The situation of classroom L2 acquisition usually restricts the L2 learner's vocabulary to the most frequent items. L2 learners may have a very limited access to natural target language input, especially when a second language is learned as a foreign language. ${ }^{1}$ (see e.g. Gilmore 2007). For this reason, target language input frequencies can be distorted to some extent in the L2 input. Although L2 learners can be exposed to different verb types in their input, the relative proportions of these types may not be the same as in the TL at large (Gor 2004; Gor \& Chernigovskaya 2005; Gor 2007). Formal instruction and

[1] The abbreviated term "L2 learner" can potentially refer to both second language learners (i. e. those who learn the language either naturalistically or in a classroom in the country where this language is spoken as an L1), as well as to foreign language learners (i.e. those who learn the language in instructional settings in a country where this language is not spoken as an L1, usually in the country of their origin) (Nizegorodcew 2007). It should be noted, however, that the distinction between different types of learners is not categorical. For this study this opposition is not relevant (see section [3] for a further description of the L2 subjects). 
focus on form can also contribute to such a distortion of input frequencies: when a particular pattern is being learned in a classroom context, it can be temporarily enhanced in the L2 input (Sharwood Smith 1993; Alanen 1995; White 1998), so that this structure can seem very frequent to L2 learners at a certain stage, while it is not necessarily as frequent in the TL at large. Since the vocabulary that is introduced in a classroom context is restricted, token frequencies of individual verbs may not be the same as the ones found in the TL at large. Most obviously, the L2 learners are exposed to the most frequent items, so that they become even more frequent in the L2 input, while the items having lower token frequencies can be even less frequent or be completely lacking in the L2 input. Thus, these differences in the L2 input can lead to the differences in generalisations that L2 learners and children can extract from their linguistic experiences.

Summarising this theoretical section, we can say that the three models that have been suggested for L2 morphological processing differ from each other on three counts: first, whether they theoretically advocate the Dual or the Single mechanism account view; second, whether they consider the principles of morphological processing in L1 and L2 as similar or different; and third, whether they assume that processing of regular and irregular morphological forms in L2 learning should be distinct or not.

\begin{tabular}{|c|c|c|c|}
\hline & $\begin{array}{l}\text { SSH } \\
\text { (Clahsen } \\
\text { \& Felser } \\
\text { 2006a,b) }\end{array}$ & $\begin{array}{l}\text { DPM } \\
\text { (Ullman } \\
\text { 2001c, } \\
2004 \text { ) }\end{array}$ & $\begin{array}{l}\text { UBA } \\
\text { (Ellis } \\
2002, \\
2003 \text { ) }\end{array}$ \\
\hline $\begin{array}{l}\text { Initial theoretical position on } \\
\text { morphological processing }\end{array}$ & $\begin{array}{l}\text { Dual } \\
\text { mecha- } \\
\text { nism }\end{array}$ & $\begin{array}{l}\text { Dual } \\
\text { mecha- } \\
\text { nism }\end{array}$ & $\begin{array}{l}\text { Single } \\
\text { mecha- } \\
\text { nism }\end{array}$ \\
\hline L2 vs. L1 morphological processing & Similar & Different & Similar \\
\hline $\begin{array}{l}\text { Differences between regular and } \\
\text { irregular processing in L2 }\end{array}$ & Different & Similar & Similar \\
\hline
\end{tabular}

TABLE 1: Theoretical positions of different theories of L2 morphological processing

The usage-based approach (UBA) that we take as a point of departure in this study advocates the Single Mechanism Account position. Consequently, we shall test whether the acquisition of verbal morphology is influenced by frequency factors. Our predictions are as follows:

(i) The verbal classes that are most frequent in the input should be acquired earlier than the verbal classes that occur rarely (type frequency effect) 
(ii) The verbal tokens that occur frequently should be acquired better than the verbs for which frequency of occurrence in the input is low (token frequency effect)

(iii) Type and token frequency effects should be found in both L1 and L2 data.

In order to address the questions concerning input frequencies, we need further to describe the target structures and analyse their distribution in the input, which we turn to in the next section.

\section{[2] RUSSIAN PRESENT TENSE MORPHOLOGY AND INPUT FREQUENCIES}

Russian is a morphologically rich language, with numerous verb classes and complex inflectional paradigms. There are two sets of inflections for conjugating verbs in the present tense form, which distinguish between $1^{\text {st }}$ and $2^{\text {nd }}$ conjugation (e.g. Švedova 1980, 647). In the Cognitive Grammar approach these alternative endings can be described in terms of schemas that allow capture of a generalisation of the two conjugational patterns (Nesset 2008).

In addition to adding the inflection of either $1^{\text {st }}$ or $2^{\text {nd }}$ conjugation, the stems of the verbs are subject to some alternations between the forms of the present tense and imperative subparadigms, in which the stem ends in a consonant, and the past tense and infinitive subparadigms, in which the stem ends in a vowel (e.g. Švedova 1980, 646, Nesset 2004, 66-67). Different types of alternations served as a basis for categorising Russian verbs into several inflectional classes (see e.g. Cornyn 1948; Jakobson 1948; Švedova 1980; Scatton 1984; Nesset 1996).

In this study we chose to focus on the acquisition of four verbal classes: -AJ-, -A-, -I-, and -OVA- (according to Jakobson's 1948 classification), as these differ in type frequency, productivity and morphological complexity and thus seem to be the most suitable for testing our hypotheses. Table 2 on the following page below characterises these four classes in terms of 1) the alternations that occur with the stem in the present tense forms in relation to the stem final segments in the infinitive/past tense forms, 2) the conjugation type, 3) the complexity of paradigm determined by the presence or absence of consonant mutations and stress shifts in the present tense forms, 4) type frequency of the inflectional class and productivity of the patterns.

The verbs belonging to the -AJ- and -A- classes look similar in the infinitive and past tense forms, however, their present tense inflectional forms differ: while the -AJ-class is morphologically simple and besides the suffix alternations $(\mathrm{a} \sim \mathrm{aj})$ no other changes occur in the stem, the -A- class is morphologically complex, having both consonant mutations and stress shifts in present tense forms. These two classes also differ in type frequency: the -AJ- class has very high type frequency and is very productive, whereas the -A- class has low type frequency (Townsend 1975; Zaliznjak 1980; Slioussar 2003). The -I- class is similar to the -A-class in its 


\begin{tabular}{|c|c|c|c|c|c|}
\hline Class & $\begin{array}{l}\text { Alternation } \\
\text { (inf/past } \sim \\
\text { present) }\end{array}$ & $\begin{array}{l}\text { Conjug. } \\
\text { type }\end{array}$ & $\begin{array}{l}\text { Morpho- } \\
\text { logical } \\
\text { complexity }\end{array}$ & $\begin{array}{l}\text { Type } \\
\text { frequency/ } \\
\text { Productivity }\end{array}$ & $\begin{array}{l}\text { Examples } \\
\text { (Inf/3pl/1sg) }\end{array}$ \\
\hline$-\mathrm{AJ}-$ & $a \sim a j$ & 1 & - & $\begin{array}{l}\text { Very high/ } \\
\text { Productive }\end{array}$ & $\begin{array}{l}\text { igrá-t } \\
\text { igráj-ut } \\
\text { igráj-u }\end{array}$ \\
\hline$-A-$ & $a \sim \emptyset$ & 1 & $\begin{array}{l}\text { Consonant } \\
\text { mutations, } \\
\text { stress shifts }\end{array}$ & $\begin{array}{l}\text { Low/ } \\
\text { Unproductive }\end{array}$ & $\begin{array}{l}\text { pisá-t } \\
\text { píš-ut } \\
\text { piš-ú }\end{array}$ \\
\hline -I- & $\mathrm{i} \sim \emptyset$ & 2 & $\begin{array}{l}\text { Consonant } \\
\text { mutations, } \\
\text { stress shifts }\end{array}$ & $\begin{array}{l}\text { High/ } \\
\text { Productive }\end{array}$ & $\begin{array}{l}\text { nosí-t nós'-at } \\
\text { noš-ú }\end{array}$ \\
\hline -OVA- & ova $\sim \mathrm{uj}$ & 1 & $\begin{array}{l}\text { Suffix } \\
\text { alternation }\end{array}$ & $\begin{array}{l}\text { Medium/ } \\
\text { Productive }\end{array}$ & $\begin{array}{l}\text { risová-t } \\
\text { risúj-ut } \\
\text { risúj-u }\end{array}$ \\
\hline
\end{tabular}

TABLE 2: Description of the four inflectional classes in Russian

morphological complexity, as many verbs belonging to this inflectional pattern have consonant mutations and stress shifts in several present tense forms, but in contrast to the -A- class, the -I- class has high type frequency (Townsend 1975; Zaliznjak 1980; Slioussar 2003). The -OVA- class can be said to have both medium morphological complexity (as this pattern involves suffix alternation -ova $\sim-u j-$ ), and medium type frequency. A particular characteristic of this class is that the suffix -OVA- can be perceived as a clear morphological cue, which can unambiguously point at belonging to this inflectional pattern. Thus, we may suggest that the morphological complexity of the -OVA-class might be compensated by the strong morphological cue, making this pattern easy to identify for the learners. However, the -OVA-verbs tend to have quite low token frequency (Gagarina 2002), which can also slow down the acquisition of this pattern (see e. g. the critical mass hypothesis in Marchman \& Bates 1994).

Since the type and token frequencies in the L2 input may differ from the distributions found in the TL at large, there is a need to analyse it in more detail. The L2 input has been analysed in three respects: 1 ) the explicit explanations on different inflectional patterns provided in the grammar books used by our L2 subjects; 2 ) the presentation of the present tense formation in the textbooks used in the instruction; 3) the distribution of the four verb classes in the L2 input, as well as correspondences in token frequency rates for the items that were included in the test. 
Two grammar books on the syllabus for Norwegian L2 learners of Russian (Mathiassen 1996; Bach Nielsen 2003) present explicitly various patterns of verbal inflections separately, and these are exemplified by several verbs for each pattern. Only one of the grammars (Mathiassen 1996) touches upon the issue of productivity of the inflectional patterns and lists five productive classes, three of them are included in this study -AJ-, -I-, -OVA-), as well as several unproductive classes, among them the -A-class. Consonant mutations and stress shifts are explained thoroughly in the grammar books. Thus, the grammar books for L2 learners provide a systematic description of the verbal system and the present tense formation of different verb types. It is, however, questionable to what extent the learners can apply this explicit information and the rules when they face a real task of conjugating a verb in the present tense (Robinson 1996).

The analysis of the textbooks used in the instruction (Bjerkeng et al. 2000; Bjerkeng \& Bräger 2002) shows that to a large extent the learners are encouraged to learn the conjugation patterns on an item-by-item basis. No explicit explanations regarding various patterns of inflections are provided in the textbooks, but different patterns are exemplified by present tense conjugational paradigms of several frequent verbs. With the exception of the -OVA- class, none of the verb classes is presented separately and prominently as a salient class. Consequently, the learners may be inclined to rely on rote learning, rather than on generation of the target forms by application of any formal rule. However, such rote learning can lead to generalisations of some patterns that occur in the input frequently enough to be represented abstractly as a schema. An important role in this process of forming generalisations is played by type frequency of the patterns (Bybee 1995).

For the purpose of this study we tried to estimate the input frequencies in the L2 input and analysed the distribution of verb types in the L2 input. This analysis is restricted to the written material used in the instruction in the beginners' course that the majority of the L2 subjects in this study took at the University of Oslo. The instructional material analysed included the following main sources: Texts in the instructional set Sosedi (Bjerkeng et al. 2000; Bjerkeng \& Bräger 2002); exercises focused on verbal conjugation and tense formation from Russian in Exercises (Chavronina \& Širočenskaja 1999, 14-33); ${ }^{2}$ the compendium used in the practical Russian and text reading class, which included authentic texts from Russian literature, fairy-tales, business documentation, dialogue examples etc.

All the verbs in the following sources were registered (approximately 5,700 forms in total), then lemmatised and tagged with grammatical information (tense,

[2] Since the learners are expected to produce the inflectional forms in the exercises, it is debatable to what extent we can call this input in the strict sense. In spite of the fact that such forms can rather be regarded as output, we consider it legitimate for our purposes to regard these uses as input, since the exercises are usually checked or completed in the classroom. 
person and number of the form used, conjugation type and inflectional class). The frequencies of the verbs belonging to the four classes focused on in this study in the TL and in L2 input are summarised in Table $3 .^{3}$

\begin{tabular}{|c|c|c|c|c|}
\hline & $-\mathrm{AJ}-$ & $-A-$ & $-\mathrm{I}-$ & -OVA- \\
\hline TL TYPE FREQUENCIES ${ }^{4}$ & $11,814(43 \%)$ & $940(3 \%)$ & $7,019(25 \%)$ & $2,816(10 \%)$ \\
\hline $\begin{array}{l}\text { L2 type frequencies: } \\
\text { Number of uses (total } \\
5,700 \text { ) }\end{array}$ & $1480(26 \%)$ & $453(8 \%)$ & $1221(21 \%)$ & $102(2 \%)$ \\
\hline $\begin{array}{l}\text { L2 TYPE FREQUENCIES } \\
\text { Number of different ver- } \\
\text { bal lexemes (total 960) }\end{array}$ & $296 \quad(31 \%)$ & $40(4 \%)$ & $225 \quad 23 \%)$ & $48 \quad(5 \%)$ \\
\hline
\end{tabular}

TABLE 3: Distribution of Russian verbs in L2 input across the four classes in focus

The distribution of the four verbal classes under consideration is different in the L2 input compared to the TL input. Although the -AJ- and -I- classes are the two largest classes both in the TL and L2 input, the difference in their type frequencies in the L2 input is less prominent. On the other hand, the type frequency of the -OVA- class is much lower in the L2 input than in the TL input, and this class is very similar to the -A- class in the type frequency rate in the L2 input. This may be due to the fact that-OVA- verbs tend to have low token frequency, and for this reason many of them do not occur in the input for L2 learners, as it is typically restricted to the most frequent lexical items. Summing up these findings, we can say that in the L2 input, the -AJ- and-I- classes have high type frequency, whereas the -OVA- and -A-classes have low type frequency.

Taking into account type frequency and morphological complexity separately, the four classes under consideration can be placed in a matrix, as shown in Table 4 on the facing page.

Several predictions can be made about the acquisition of these classes by Russian children and L2 language learners. Isolating the frequency factor from morphological complexity, the predictions formulated below regard rates of correct

[3] The counts represented here include all verb forms, rather than only present tense forms. The argument for doing this is that the glossaries to the textbooks provide the information on other forms, which are sufficient for figuring out the whole present tense paradigm of the verb. The observations made in the classroom have also shown that the teacher tended to explicitly provide the present tense forms for new verbs that occurred in the texts.

[4] The numbers here are based on the database counts performed on Zaliznjak's Grammatical Dictionary, which includes 27408 verbs. Due to some inconsistencies found in the referred sources (Slioussar 2003; Gor 2004) the numbers here are approximations. 


\begin{tabular}{lll}
\hline & High type frequency & Low type frequency \\
\hline Low morphological complexity & -AJ- & $-\mathrm{OVA}^{-5}$ \\
High morphological complexity & -I- & $-\mathrm{A}-$ \\
\hline
\end{tabular}

TABLE 4: Type frequency and morphological complexity of the four Russian classes

stem recognition, rather than correctly produced forms.

(i) The two classes with high type frequency, the -AJ- and -I- classes, should be acquired better and earlier by the learners. As these classes have relatively high type frequency in both TL and L2 input, we do not expect any differences between the children acquiring Russian as their L1 and adult L2 learners of Russian.

(ii) The two most frequent patterns are also expected to be applied more frequently to nonce verbs, as well as serve as a basis for overgeneralisation errors.

(iii) The -A- class, having the lowest type frequency and being morphologically complex, should be acquired later by the children, and L2 learners may have problems with mastering this pattern.

(iv) Since the type frequency of the -OVA- class turned out to differ in the TL and L2 input, we can expect to find some differences in the acquisition of this class by children and by adult L2 learners.

\section{[3] METHODOLOGY}

\section{[3.1] Subjects}

Four groups of informants participated in the study: three groups of Russian children (aged 4, 6 and 8) and one group of Norwegian learners of L2 Russian (Table 5 on the next page). The children were recruited for the experiment from several kindergartens and schools in St. Petersburg. The Norwegian learners of L2 Russian were all recruited from the Russian language programme at the University of Oslo.

The L2 learners in the study, although they were all recruited from the same educational programme, varied to some extent in several respects. With one exception, the age of the L2 learners was between 20 and 30 years old. The vast majority of the subjects studied Russian intensively (classes 4-5 days a week). The

[5] Although the-AJ- and-OVA-classes are not exactly on the same level of morphological complexity (since the -OVA-class involves the suffix alternation), as we claimed above, this can be compensated by the strong morphological cue, helping the learners to identify the -OVA-class and inflect its members correctly. 


\begin{tabular}{lccc}
\hline Group & Number of subjects & Males & Females \\
\hline Russian children 4 y. o. & 30 & 15 & 15 \\
Russian children 6 y. o. & 30 & 15 & 15 \\
Russian children 8 y. o. & 21 & 11 & 10 \\
Adult L2 learners & 25 & 10 & 15 \\
\hline
\end{tabular}

TABLE 5: Overview of subjects in the study

majority of them had visited Russia for at least several weeks, whereas some lived in Russia for longer periods of time (1-3 months on average). With the exception of four subjects who studied Russian at high school, all other subjects started learning Russian at the University. The overall period the subjects were studying Russian varied from $0.5-6$ years.

\section{[3.2] Testing material and procedure}

All subjects were tested orally and individually with the same test battery, which consisted of two tests. The content in the tests was the same, but they differed in the form the stimuli were presented: in one of the tests the stimuli were presented in the infinitive, in the other - in the past tense plural form. The order of the tests and the order of the stimuli in each of them were controlled for: approximately half of the subjects performed the infinitive test first, and then the past tense test, and the other half was tested in the reverse order; the order of the verbs within the tests was random, furthermore, the order of the stimuli was counterbalanced, so that within each group half of the participants received the items in one order, and the other half in the other.

The testing material included 80 verbal stimuli in each test, evenly representing four Russian inflectional classes: -AJ-, -A-, -I-, -OVA- (described above). Half of the stimuli were real Russian verbs, and half were nonce verbs. Nonce verbs were created by changing the initial consonant segments of the real verbs, and they were meant to test the subjects' ability to generalise the inflectional patterns and use them productively. Within each class the real verbs were balanced for token frequency, at least for the TL at large. Token frequency counts were based on the Russian Frequency Dictionary (Zasorina \& Agraev 1977).

Separate counts were performed to estimate the token frequency of the stems in the test for L2 learners, based on the materials included in the analysis in the previous section. The verbs in the test of which the stems had at least four occurrences in the sample were considered as having a high token frequency, while the verbal stimuli of which the stems occurred in the corpus less than four times or did not occur at all, were considered as low token frequency. With the exception of 8 items, L2 token frequency rates turned out to coincide with the token 
frequency rates for the TL at large. We didn't consider this difference to be significant, and thus use the same token frequency rates in our analysis of results from both children and L2 learners, which also allows for a more accurate comparison between the groups.

The testing procedure was based on a design first used in Berko (1958): the subjects were shown a picture to each stimuli, and the experimenter told them either what the figures in the pictures like to do (in the infinitive condition), or what they were doing yesterday (in the past tense condition). The target forms for responses were present tense forms 3rd person plural and 1st person singular, these forms were elicited by asking the subjects to say what the figures in the pictures ARE doing ( $3 \mathrm{pl}$ ), and then say the same thing about themselves (1sg). The testing was audio-taped, and later the responses were transcribed and systematically coded.

\section{[3.3] Measurements of subjects' performance}

We present the results on the subjects' performance in the tests measured on several main variables: total correct performance; correct stem recognition for each inflectional class; correctly produced forms for high and low token frequency verbs in each class; and generalisation patterns in responses to nonce stimuli.

The difference between measuring correct performance in terms of stem recognition vs. correctly produced forms needs a more detailed explanation. Measuring the performance in terms of correct stem recognition is done in order to eliminate the influence of the morphological complexity and thus assess the performance on different verb classes on a fair basis. The -A- and -I- classes are morphologically complex and involve consonant mutations and stress shifts in the present tense paradigm, which can result in lower rates of correctly produced forms. For example, for the verb pisát (write) the correct target forms are pišut (3pl) and pišú (1sg). Only these forms are considered correct in terms of correctly produced forms. On the other hand, when either consonant mutations are missing (pisut*, pisú*), or stress shifts are incorrectly applied (pišút*, pišu*), or both (pisút*, pisu*) the responses are incorrect in form, but they still can be considered correct in terms of stem recognition. When a wrong inflectional pattern is applied to an item, the responses are considered incorrect in terms of stem recognition: e. g. pisájut*, pisáju* (-AJ- pattern is applied to a verb from the -A- class).

\section{[4] RESULTS}

\section{[4.1] Total correct performance}

Total correct performance in two Russian tests for four subject groups is illustrated in Figure 1 on the following page.

The figure shows that all subjects' performance was better in the test with the stimuli in the infinitive, than with the stimuli in the past tense form. For 
Total correct performance

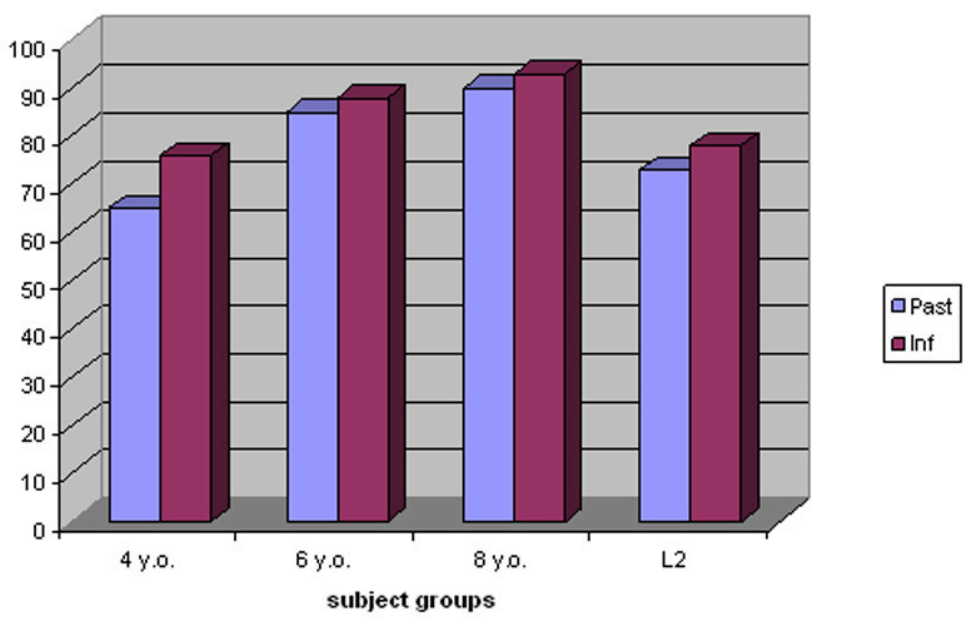

FIGURE 1: Total correct performance in the infinitive and past tense Russian test

L2 learners this difference might probably be explained by the influence of their learning setting: first, the infinitive is a base form cited in the dictionaries and for this reason this form may seem more prominent for L2 learners; second, in the tasks offered in the instruction, L2 learners typically generate inflectional forms from the infinitive. Thus, they are more used to this task than to a task of generating present tense forms from the past tense of the verbs. For the children, however, we should look for a different source of this unbalanced performance in the infinitive and past tense conditions.

We suggest several potential reasons for the children's better performance in the infinitive compared to the past tense condition. One possible explanation could be that the past tense forms occur less frequently in their input than the infinitives. However, according to an assumption expressed in Nesset (2004, 70), "while the infinitive is the citation form used in grammars and dictionaries, ...the more frequent past tense forms enjoy a more central status in speakers' and hearers' mental grammars". However, due to lack of any corpora of child-directed speech which could be used to test this assumption empirically, this explanation cannot be taken as plausible. Another potential explanation for this fact might lie in a higher cognitive complexity of a reference to past events as compared to "here and now". Our data suggest that some children had difficulties in distinguishing past and present forms in the test, which mirrored in more frequent repetitions of the stimuli in the past tense condition, especially for the youngest age group. This can be a result of an incomplete acquisition of the category of aspect: all the stimuli in the test were imperfectives, and previous studies on acquisition 
of Russian have provided evidence that young children may associate all imperfectives (either in the present or past tense) with incomplete events (KiebzakMandera et al. 1997; Protassova 1997; Ceytlin 2000; Kiebzak-Mandera 2000; Gagarina 2003). It should be noted, that in principle the design of the task allowed for the use of the past tense forms in responses (e.g. $X$ and $Y$ painted yesterday. Can you tell me what they do/are doing (in the picture) today? - Today they also painted). In such cases the experimenter usually insisted on a different response by stressing the present tense context with an adverbial 'now' instead of 'today', but in Russian it is not ungrammatical to use the past tense form with the adverbial 'now' (in the meaning that they have just been doing something), and some of the children failed to recover from the repetition of the stimuli even in such more accurate and enhanced present tense contexts.

In order to find out whether the differences in total correct performance were significant, and whether they hold across the groups, a mixed between-within subjects design ANOVA was performed with TEST as a within-subject variable with two levels (past tense condition vs. infinitive condition), and AGE and SEX as between-subject variables. We found a significant effect for TEST (Wilks' lambda $=.692, F(1,98)=43.6, p<.0005)$ and for interaction TEST $\times$ AGE (Wilks' Lambda $=.854, F(3,98)=5.575, p=.001)$. Among the between-subjects variables, the results revealed a statistically significant effect for $\operatorname{AGE}(F(3,98)=26.359, p \leq$ .0005). Post hoc comparisons using the Tukey HSD test have shown that 4-yearold Russian children differed significantly from 6- and 8-year-old children on total correct performance ( $p \leq .0005$ ), while the difference between Russian 6-yearolds and 8-year-olds turned out to be not statistically significant $(p=.254)$. The L2 learners' total correct performance was not significantly different from Russian 4-year-olds ( $p=.191)$, but was significantly different from 6- and 8-year-old Russian children $(p \leq .0005)$.

\section{[4.2] Correct stem recognition rates for different verb classes}

Further, we compared correct recognition by verb type across the subject groups. Means for correct stem recognition for each class in two tests and by subject groups are illustrated in Figure 2 on the next page. A mixed between-within subjects design ANOVA was performed with two within-subject variables - CLASS (AJ-, -I-, -OVA-, -A-) and TEST (past condition vs. infinitive condition), and two between-subjects variables - AGE ( 4 y.o. children, 6 y.o. children, 8 y.o. children, L2 learners), and SEX (male vs. female). This statistical analysis revealed the main effects for CLASS (Wilks' Lambda $=.204, F(3,96)=124.736, p \leq .0005)$ and TEST (Wilks' Lambda $=.712, F(1,98)=39.631, p \leq .0005$ ), and several interaction effects: CLASS $\times$ AGE (Wilks' Lambda $=.376, F(9,234)=12.865, p \leq .0005)$, TEST $\times$ AGE (Wilks' Lambda $=.844, F(3,98)=6.046, p=.001)$, CLASS $\times$ TEST (Wilks' Lambda $=.816, F(3,96)=7.202, p \leq .0005)$. These results suggest that 
the subject groups recognised the four verb classes differently, and there were also significant differences in correct stem recognitions depending on the test condition (past vs. infinitive). A general trend we observe is that the verbal classes were recognised better in the test with stimuli in the infinitive than in the past tense form, with the exception of correct stem recognitions for the -AJclass by L2 learners.

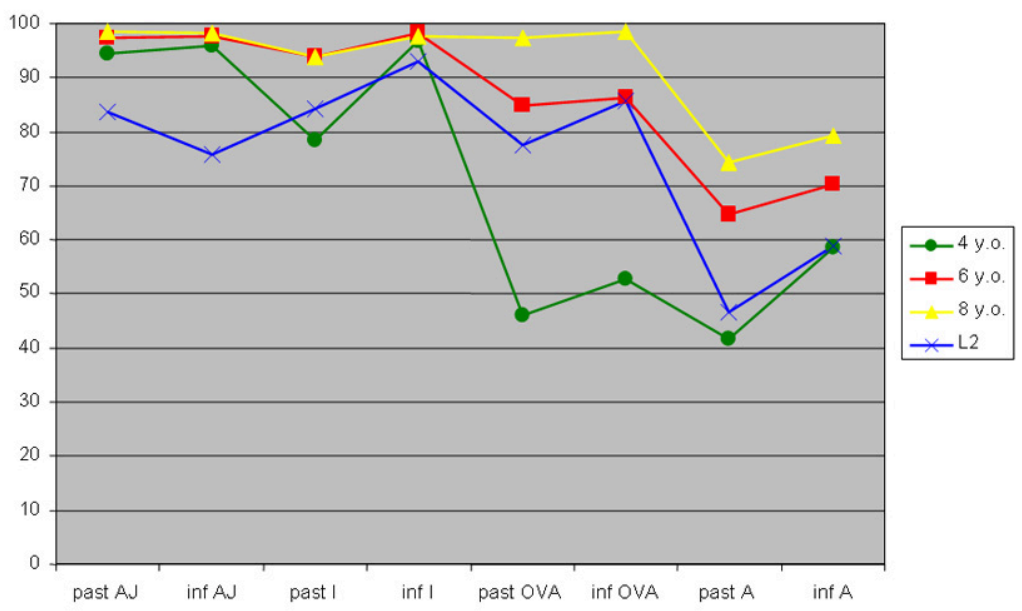

FIGURE 2: Correct stem recognition of different classes real verbs in two Russian tests by subject groups

As Figure 2 shows, all groups of Russian children in both tests recognised the -AJ- class close to $100 \%$ correct, and their means are much higher than that for L2 learners. These results suggest that by the age of four the Russian children have mastered the -AJ- class, while L2 learners lag significantly behind in their correct recognition of this class. Post hoc comparisons reveal that L2 learners' means of correct recognition for this class is significantly lower than the means for Russian children ( $\mathrm{p} \leq .0005$ for all pairs).

For the -I- class the means for correct stem recognition are higher in the infinitive condition than in the past tense condition, i.e. there is a significant effect for TEST (Wilks' Lambda $=.724, F(1,102)=38.945, p \leq .0005$ ) as well as interaction effect TEST $\times$ AGE (Wilks' Lambda $=.847, F(3,102)=6.16, p=.001) .6$ - and 8-year-old Russian children recognised the -I- verbs better than 4-year-old children and L2 learners, especially in the past tense condition. Post hoc comparisons confirm this finding: the difference between 4-year-old children and Norwegian L2 learners of Russian is not statistically significant $(p=.973)$, whereas these groups' performance on -I-class is significantly lower than that of 6- and 8-yearolds. Nevertheless, L2 learners and 4-year-olds' rates of stem recognitions are also relatively high on I-class. 
Thus far, the results on correct stem recognition of the two most frequent classes, the -AJ- and -I- classes, show that all subject groups have high rates of stem recognition of these stems. The -AJ-class is recognised slightly better than the -I- class, especially in the past tense test condition and by 4 -year-old children. On the other hand, L2 learners have a higher percentage of correct recognitions for the -I- class in the infinitive test condition than for the -AJ- class, which can probably be explained by their stronger reliance on the potential morphological cue - the verbs of the -I- class have a different thematic vowel (- $i-)$, than all other stimuli in the test, which all end in -at/-ali and thus can represent a competition of the -AJ-, -A- and -OVA- inflectional patterns.

We can see more variation between the groups in the results on the less frequent-OVA- and-A-classes. As Figure 2 on the preceding page illustrates, correct stem recognition of the -OVA- class is distinctly lower for 4-year-old Russian children than for all other subject groups, and this difference is statistically significant ( $p \leq .0005$ for all groups), while the difference between 6 - and 8-year-old children does not reach statistic significance ( 6 y. o.-8 y. o. $p=.127$ ). L2 learners performed on -OVA- verbs close to 6-year-old Russian children, the difference between their means was not statistically significant $(p=.886)$, but L2 learners' performance was significantly lower on the -OVA- class than that by Russian 8year-olds $(p=.031)$.

These findings suggest that by the age of four, Russian children have not yet acquired the -OVA- pattern. Presumably, this inflectional pattern is acquired later, between the ages of four and six, because already at the age of six we observe a drastic increase in correct performance on this class. These findings are consistent with the results of the earlier studies of acquisition of Russian verbal morphology by children, which report that "there is an abrupt jump in the rates of stem recognition for the -OVA- class between the ages of 4 and 5" (Gor \& Chernigovskaya 2004, 6). Concerning L2 learners, as expected due to low type frequency of this pattern in the L2 input, they were worse at recognising the -OVApattern than the most frequent -AJ- and -I- patterns in the past test condition; however in the infinitive test condition the rates of correct stem recognition of the -OVA- pattern (86\%) are higher than correct stem recognition of the frequent -AJ- class (76\%). This fact can probably be explained by the influence of a clear morphological cue (suffix -ova- in the infinitive and past tense forms) that characterises this inflectional class, which was also made prominent in the L2 instruction, as discussed earlier.

Figure 2 illustrates clearly that the rates of correct stem recognition of the least frequent -A- class are noticeably lower for all subject groups compared to their correct stem recognition rates of the other three classes we considered before. Even 8-year-old Russian children, who seem to be the most proficient group, performed below $80 \%$ correct on this class. These results suggest that the $-\mathrm{A}-$ 
class, having the lowest type frequency and the high degree of morphological complexity, has not yet been completely acquired by this age by monolingual Russian children. As seen in the figure, Russian 4-year-old children and L2 learners have a remarkably low rate of correct stem recognition of this class, while the recognition rate of 6-year-old and 8-year-old Russian children gradually becomes better. Post hoc comparisons show that the difference between 4-year-olds and L2 learners is not statistically significant $(p=.944)$, and that these groups differ significantly from $6-$ and 8-year-olds (4 y. o.- 6 y.o $p=.001 ; 4$ y. o.-8 y. o. $p \leq .0005$; L2-6 y. o. $p=.010$, L2-8 y. o. $p \leq .0005)$. These results demonstrate, that the class with the lowest type frequency and high morphological complexity is acquired late and is recognised correctly less frequently by all groups of subjects.

The results on correct stem recognition suggest that there is a similarity between L1 and L2 acquisition and processing of verbal morphology: there is a correlation between the type frequency of the pattern and the rates of correct stem recognition for all groups. However, L2 learners do not match any of the child age groups completely, which can be explained by the influence of formal instruction, as well as the differences found in the distribution of type frequencies in the L2 input.

\section{[4.3] Generalisations in response to nonce verbs}

In the previous section we have demonstrated that the rates of correct recognition of a particular class correlate strongly with the type frequency of this particular inflectional pattern. Although this can be an indication of the importance of type frequency in the order of acquisition of different inflectional patterns, to make this point stronger we need to analyse which patterns the subjects preferred in their responses to nonce verbs. In order to conjugate a nonce verb, the subjects are supposed to apply a particular abstract schema which has emerged on the base of the real verbal items from the subjects' previous linguistic experience. The actual usage of different verbs leads to formation of several schemas. Thus, the subjects are faced with a problem of choice between several schemas which may be available. According to Bybee $(1995,430)$, "the likelihood of the schema being extended to new items is directly dependent upon two factors: (i) the defining properties of the schema and (ii) its strength, the latter property being derivable from the number of items that reinforce the schema", "the higher the type frequency of the pattern described in the schema, the greater are its chances of applying to new items".

Potentially, any of the existing schemas could be applied to nonce items provided that the nonce item meets the properties of the schema. However, the schemas which were applied most frequently by the majority of the subjects were the schemas representing the four inflectional classes under consideration. For 
this reason we decided to focus on these four generalisation patterns and exclude from our analysis other types of responses. ${ }^{6}$ The four generalisation patterns we consider here are described in Table 6 on the following page.

As described in section [3], half of the Russian tests consisted of nonce verbs (i. e. 40 nonce verbs in each of the tests). Nonce verbs were created from real verbs, and each of them was classified as belonging to one of the four classes (-AJ, -A-, -I-, -OVA-): e.g. a nonce stimuli kisat matched the real verb pisat 'write' and thus was classified as a nonce verb in the -A-class). However, as long as the final segment of verbs belonging to the -AJ-, -A-, and -OVA-classes is the same (-at/-ali) in the stimuli, potentially any of these three inflectional patterns could be applied to nonce verbs. It is less likely that any of these three patterns with the thematic vowel - $a$ - would be applied to the nonce verbs which have a thematic vowel $-i$ in the stem (i. e. nonce verbs from the -I- class). The schema representing the -Iclass has different properties, and it is thus not expected that it will be applied to more than $25 \%$ of the nonce items.

If type frequency influences the choice of one of the schemas for application to nonce stimuli, we can expect that the frequent patterns are used for generalisations more often than the patterns that have low type frequency. Thus, we can expect a general trend that the -AJ- and -I- patterns are generalised frequently by all subject groups; whereas the least frequent -A- pattern will not be frequently applied to nonce verbs.

The percentages of generalisations of the -AJ-, -A-, -I- and -OVA- inflectional patterns are illustrated in two figures below. Figure 3 on page 301 illustrates the proportions of generalisations used for the nonce verbs in the test with stimuli in the past tense, whereas Figure 4 on page 301 illustrates the proportions of generalisations in the test with stimuli in the infinitive.

The figures show a general tendency of preference for GEN>-AJ- in response to nonce verbs, however the relative proportions of -AJ- generalisations differed across groups and depending on the test. To estimate effects of within- and betweensubjects variables a mixed between-within subjects ANOVA was performed with TEST (past vs. infinitive) and GENERALISATION TYPE (AJ, A, I, OVA) as withinsubject variables, and AGE (4 y. o., 6 y. o., 8 y. o. and L2 learners) and SEX (male vs. female) as between-subjects variables. The statistical analysis revealed statistically significant main effects for TEST (Wilks' Lambda $=.699, F(1,98)=42.112$, $p \leq .0005$ ), GENERALISATION TYPE (Wilks' Lambda $=.196, F(3,96)=131.158$, $p \leq .0005)$ and $\operatorname{AGE}(F(3,98)=8.812, p \leq .0005)$, as well as interaction effects for TEST $\times$ AGE (Wilks' Lambda $=.789, F(3,98)=8.715, p \leq .0005$ ), GENERALISATION TYPE $\times$ AGE (Wilks' Lambda $=.624, F(9,234)=5.556, p \leq .0005)$,

[6] These other response types to nonce verbs included not only the applications of other inflectional patterns than those we consider here, but also responses when the subjects replied in the past form or infinitive, which we considered as "repetition of the stimuli". 


\begin{tabular}{|c|c|c|c|}
\hline Generalisation type & Description & \multicolumn{2}{|c|}{$\begin{array}{l}\text { Examples (inf/past plural } \\
\text { - present } 1 \mathrm{sg} / 3 \mathrm{pl} \text { ) }\end{array}$} \\
\hline$G E N>-A J-$ & $\begin{array}{l}\text { The form is generated by } \\
\text { adding -j- to a stem with a } \\
\text { thematic vowel }-a-\text {, before } \\
\text { adding the ending. }\end{array}$ & $\begin{array}{l}\text { kisa-t/kisa-li } \\
\text { kisaj-u/kisaj-ut } \\
\text { mylova-t/mylova-li } \\
\text { mylovaj-u/mylovaj-ut }\end{array}$ & - \\
\hline$G E N>-I-$ & $\begin{array}{l}\text { The form is generated by } \\
\text { adding the ending directly } \\
\text { to the stem (either with } \\
\text { or without consonant } \\
\text { mutations) with a the- } \\
\text { matic vowel -i- (the vowel } \\
\text { is eliminated before the } \\
\text { endings). }\end{array}$ & $\begin{array}{l}\text { nadi-t/nadi-li } \\
\text { naž-u/nad-at }\end{array}$ & - \\
\hline$G E N>-A-$ & $\begin{array}{l}\text { The form is generated by } \\
\text { adding the ending directly } \\
\text { to the stem (either with } \\
\text { or without consonant mu- } \\
\text { tations) with a thematic } \\
\text { vowel -a- (the vowel is } \\
\text { eliminated before the end- } \\
\text { ings). }\end{array}$ & $\begin{array}{l}\text { kisa-t/kisa-li } \\
\text { kis/š-u/kis/š-ut } \\
\text { okoža-t/okoža-li } \\
\text { okož-u/okož-ut } \\
\text { tintova-t/tintova-li } \\
\text { tintovl-u/tintov-ut }\end{array}$ & - \\
\hline GEN>-OVA- & $\begin{array}{l}\text { The form is generated us- } \\
\text { ing the suffix -uj- before } \\
\text { the ending. The stimuli do } \\
\text { not necessarily have the } \\
\text {-ova- suffix in the infini- } \\
\text { tive/past tense stem. }\end{array}$ & $\begin{array}{l}\text { kisa-t/kisa-li } \\
\text { kisuj-u/kisuj-ut } \\
\text { tintova-t/tintova-li } \\
\text { tintovuj-u/tintovuj-ut } \\
\text { tintova-t/tintova-li } \\
\text { tintuj-u/tintuj-ut } \\
\text { nadi-t/nadi-li } \\
\text { naduj-u/naduj-ut }\end{array}$ & - \\
\hline
\end{tabular}

TABLE 6: Generalisation types 


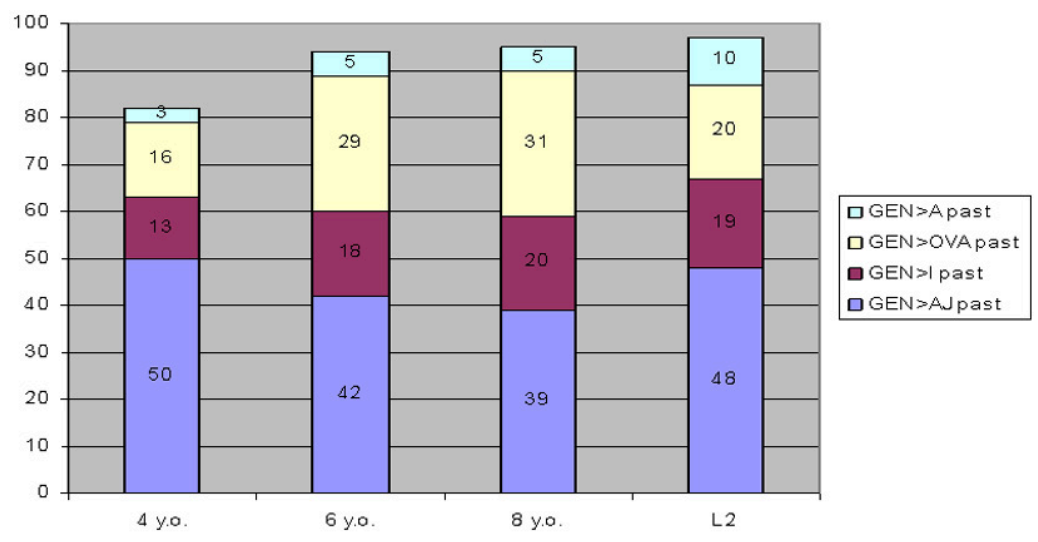

FIGURE 3: Generalisations in responses to nonce verbs (past test condition)

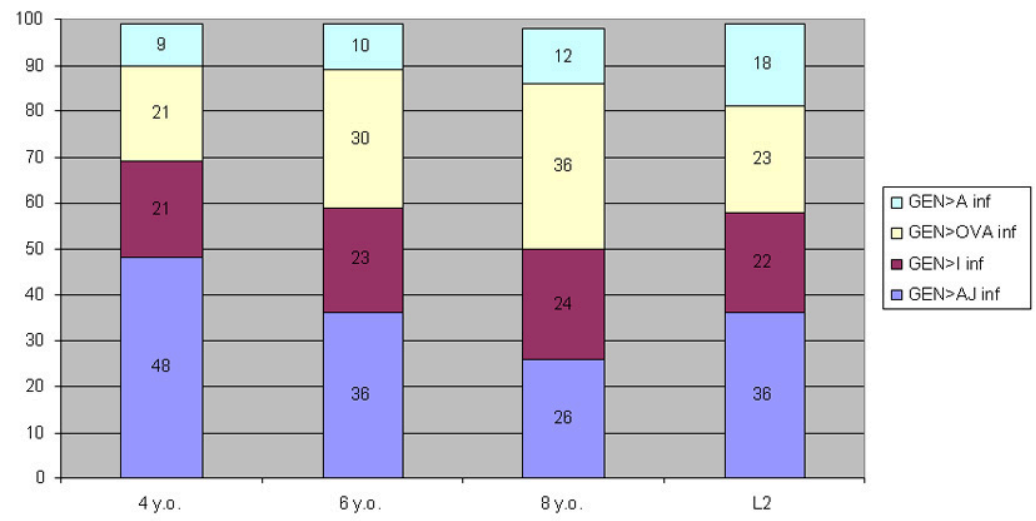

FIGURE 4: Generalisations in responses to nonce verbs (infinitive test condition)

and TEST $\times$ GENERALISATION TYPE (Wilks' Lambda $=.590, F(3,96)=22.197$, $p \leq .0005)$. These results suggest that the differences in generalisation types found between the subject groups are significant, and that the generalisation types used differed depending on the test condition, whereas the subjects' responses did not depend on their sex.

Although the -AJ-generalisations are the most frequent for all subject groups, we can observe a tendency that the use of this pattern is higher in the past tense than in the infinitive condition, and with age the percentage of -AJ- generalisations decreases. Post hoc comparisons using the Tukey HSD test show significant difference between 4-year-old children and 6- and 8-year old children (4 y. o.-6 y. o. $p=.013,4$ y. o. -8 y. o. $p \leq .0005)$. L2 learners generalised the -AJ- pattern in their responses to nonce verbs to the same extent as Russian 4-year-old and 6-year-old children (L2 vs. 4.y. o. $p=.173$; L2 vs. 6 y. o. $p=.804$ ), but differently 
from Russian 8-year-olds ( $p=.042)$.

As seen in Figure 3 on the previous page and Figure 4 on the preceding page, the use of the-AJ- pattern exceeds $25 \%$, which means that this productive pattern was applied not only to nonce stimuli classified as belonging to the -AJ-class, but also to other nonce stimuli. Most frequently, it was applied to a large part of the -A- stimuli, as the rate for -A-generalisations is extremely low, but it could also be applied to -OVA- nonce stimuli, especially by 4-year-old children who have not yet acquired the -OVA- inflectional pattern. This explains the higher use of the -AJ- generalisation by 4-year-old children.

The -I-class pattern is also applied to nonce verbs quite frequently by all subjects. Although the proportions of -I- generalisations are not very high in the figures, we should bear in mind that the schema representing this inflectional pattern has restrictions in terms of the thematic vowel, so potentially it could only be applied to $1 / 4$ of all nonce verbs included in the test. The figure illustrates that the application of the -I- pattern is close to $25 \%$ for all subject groups. Post hoc comparisons reveal that the differences in the use of -I- generalisations were significant for 4-year-old children as compared to all other groups ( 4 y. o.-6 y. o. $p=.043,4$ y. o. -8 y. o. $p=.002,4$ y. o.-L2 $p=.025$ ).

This result may seem surprising in the light of the high type frequency of this pattern and also quite high rates of stem recognition of the -I- class which we reported on in the previous section. This can probably be explained by two facts:

(i) 4-year-old children tended to reply with repetition of the stimuli, either in the infinitive or the past tense form, more often than other subject groups (repetitions of the stimuli occurred at the rate of up to $10 \%$ for real and nonce -I- verbs together)

(ii) 4-year-old children tended also to overuse a general V+j strategy in their replies, so that when this strategy was applied to the verbs of the -I- class, the results were coded as generalisations of the -IJ- pattern, which could also have resulted in the lower rates of -I- generalisations.

L2 learners replied to most nonce -I- verbs with an appropriate inflectional pattern: the -I- generalisation rate is $19 \%$ in the past test, and $22 \%$ in the infinitive test. Post hoc comparisons have shown that these rates are significantly different from the rates of 4-year-old children $(p=.025)$, but they do not reach significance as compared to -I- generalisations used by 6 -year-old children $(18 \% / 23 \%)(p=$ $.987)$ and by 8 -year-old children $(20 \% / 24 \%)(p=.792)$.

The analysis of generalisations of the -OVA- inflectional pattern should also be related to our previous findings on correct stem recognitions. The results on generalisations used in responses to nonce verbs show in fact that 4-year-old children did apply this inflectional pattern in $16 \%$ and $21 \%$ in the past and infinitive 
test conditions, respectively. However, they differ significantly in their use of this generalisation pattern from 6 - and 8-year-olds ( 4 y. o.-6 y. o. $p=.001,4$ y. o.-8 y. o. $p \leq .0005$ ), who tend to apply this pattern not only to -OVA- nonce verbs, but also to nonce verbs from other classes (because their rates exceed 25\%).

L2 learners' productive use of the -OVA- pattern is not significantly different from that of 4-year-old Russian children $(p=.767)$, but is significantly different from 6- and 8-year-old children (L2-6 y. o. $p=.032$, L2-8 y. o. $p=.001$ ). As we already discussed above, the -OVA-class turned out to match the -A-class in type frequency, and in contrast to the TL input frequencies, the -OVA-class turned out to have low type frequency in the L2 input. On the other hand, the L2 learners could have acquired this low frequent pattern due to prominence and enhancement of this pattern in the L2 instruction - this was the only class which was explicitly presented as a salient pattern. This might have helped the L2 learners to form proper generalisations and a schema, which they seem to apply to nonce items in the test.

The figures demonstrate clearly that the -A- pattern was the least preferred generalisation pattern in all subject groups, which can be explained by combination of low type frequency of the -A- class and high degree of morphological complexity. We can also observe that the percentage of -A-generalisations increases gradually with age for Russian children. L2 learners have the highest percentage of generalisations of the -A- pattern in both tests ( $10 \%$ in the past test, $18 \%$ in the infinitive test), and their results are significantly different from 4- and 6-yearold children (L2-4 y. o. $p=.003$, L2-6 y. o. $p=.021$ ), but similar to 8-year-old children $(p=.107)$. This may be surprising taking into consideration that the -A- class has low type frequency in the L2 input. One possible explanation for this can be ascribed to the influence of formal instruction and focus on form. As mentioned earlier, a special focus in the L2 instruction is given to verbal forms that have "irregular" conjugational patterns, i. e. the patterns which have consonant mutations and stress shifts. This focus on irregularities could have made this low frequency pattern with consonant mutations and stress shifts more enhanced in the L2 input, so that L2 learners were inclined to pay more attention to this pattern and be aware of the morphological complexities it implies. Maybe therefore they were deliberately trying to apply this pattern to nonce verbs more frequently than other subject groups.

Our analysis of generalisation patterns suggests that type frequency is important in the subjects' choice of the schema to be applied to nonce verbs: the most frequent -AJ- pattern is preferred for generalisations. However, the correlation is less evident due to the possible influence of other factors. L2 learners showed higher percentages of use of low type frequency -A- and -OVA- patterns to nonce verbs than was expected. We have shown that these findings can be explained by the influence of formal instruction and focus on form, which is the case in second 
language acquisition in a classroom setting.

\section{[4.4] Influence of token frequency}

Thus far, we have discussed the effects of type frequency on correct stem recognition and use of different patterns for generalisations in responses to nonce verbs. As pointed out by the theoretical framework we take as a departure point in this study, token frequency is also an important factor which can play a role in acquisition. Within the usage-based account we expect that token frequency effects can be found in all verb types in both L1 and L2 acquisition. We consider separately token frequency effects in rates of correct stem recognition and in rates of correctly produced forms.

As was described in the methodology section, each inflectional class in the test was represented by 5 verbs having high token frequency and 5 verbs having low token frequency. Thus, we will look here at whether the subjects recognised high token frequency verbs better than low token frequency verbs, and whether this tendency was similar for all subject groups and for all types of verbs. Correct stem recognition rates for high token frequency and low token frequency verbs in the two test conditions are illustrated in the following figures: Figure 5 for 4-year-old Russian children, Figure 6 on the facing page for 6-year-old Russian children, Figure 7 on page 306 for 8 -year-old Russian children, and Figure 8 on page 306 for L2 learners. With several exceptions, where the recognition rates for low and high token frequency stimuli are close to equal, we can observe a tendency that the high token frequency verbs were recognised better than the low token frequency verbs. This trend holds across subject groups, in both tests and mostly for all verb classes.

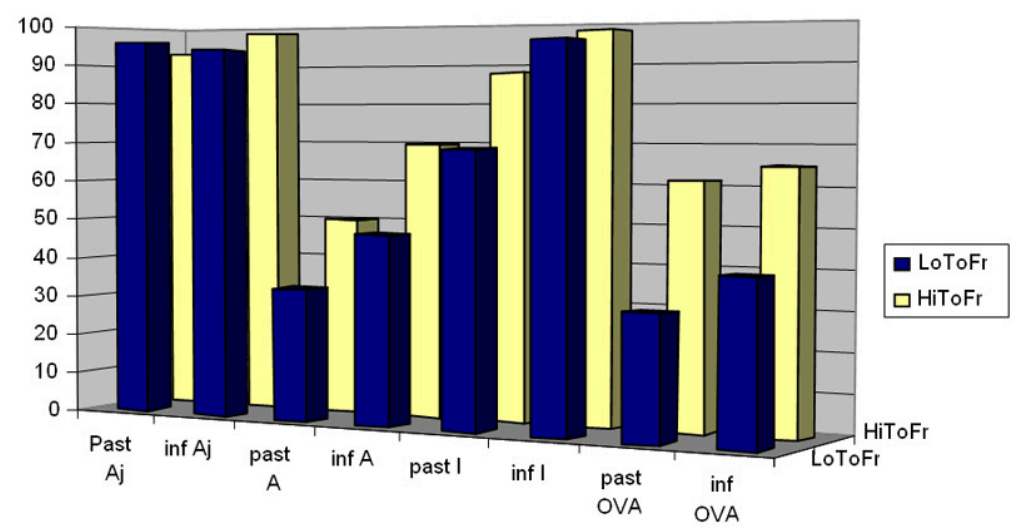

FIGURE 5: Token frequency effects in correct stem recognition rates for 4-year-olds 


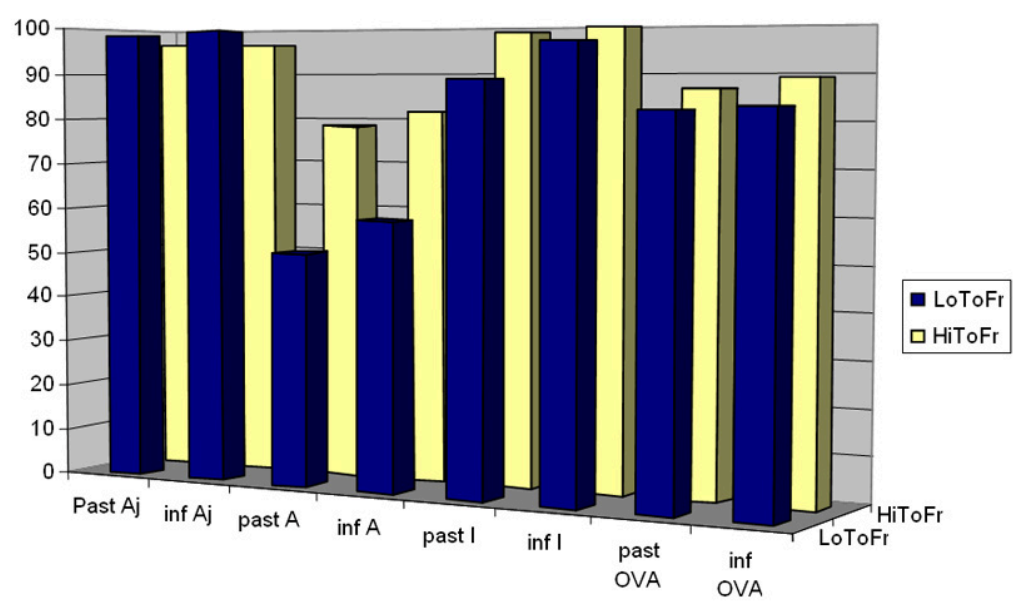

FIGURE 6: Token frequency effects in correct stem recognition rates for 6-year-olds

To check whether the differences visible in the figures are statistically significant, a series of paired-samples t-tests were performed on the data, in which we compared 8 pairs for every subject group ( 4 classes $\times 2$ tests, high token frequency vs. low token frequency items). This statistical analysis has shown that not all the differences between high token frequency items and low token frequency items reach the level of statistical significance. Token frequency effects did not reach statistical significance for the-AJ-class in either test condition for all Russian children nor for L2 learners in the past test condition. Token frequency effects again did not reach statistical significance for the -I- class in the infinitive test condition for all groups Russian children, nor in either test condition for L2 learners; nor for the-OVA- class for children at the age 6 and 8 in either test conditions.

At first sight these findings can provide evidence against token frequency effects in some classes, but a closer look reveals an interesting tendency: token frequency effects appear to be non-significant for the inflectional classes on which the subjects perform close to asymptote, i.e. the better in general the subjects perform on a particular class, the less evident are token frequency effects and the subjects tend to perform equally well on both high and low token frequency verbs. A similar finding has been reported in the previous studies which investigated token frequency by regularity interaction, in particular, it was claimed that token frequency effects are evident for all types of inflections (regular and irregular), but frequency effects can disappear and become less visible as the performance is close to asymptote (Ellis 1998). This is the case for our data: relating our findings on token frequency effects to the results on correct stem recognition rates for different classes across subject groups, we can notice that token frequency 


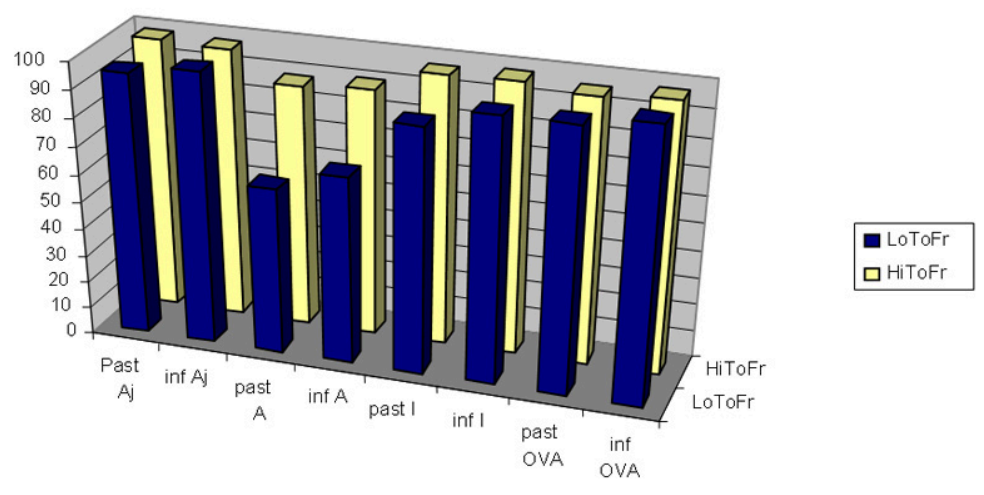

FIGURE 7: Token frequency effects in correct stem recognition rates for 8-year-olds

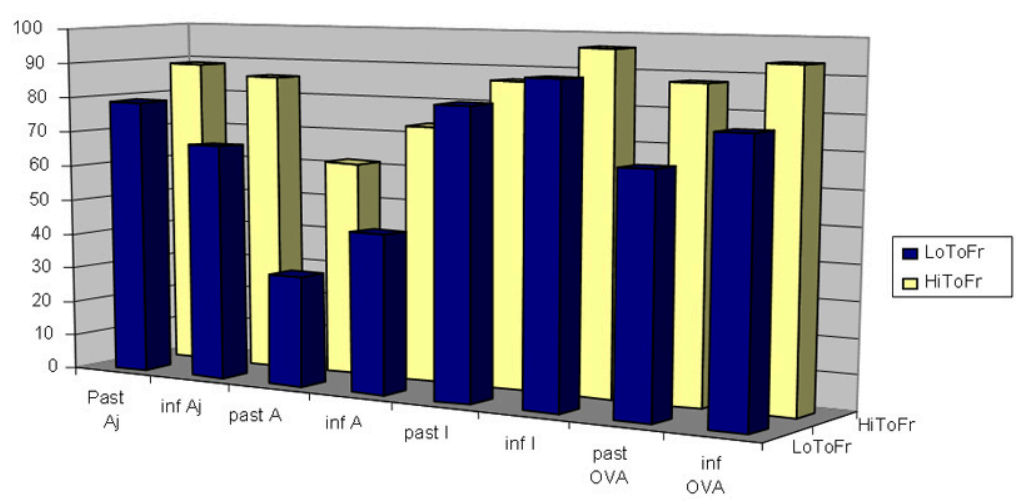

FIGURE 8: Token frequency effects in correct stem recognition rates for L2 learners

effects turned out to be statistically insignificant when the rates of correct stem recognition were higher than $80 \%$.

Thus, our findings do not contradict the predictions of the single-mechanism account that token frequency influences the acquisition of all verbal classes.

We predicted as well that token frequency will influence percentages of correctly produced forms in both L1 and L2 acquisition. The figures below illustrate correctly produced forms for each inflectional class in two test conditions for high and low token frequency verbs: Figure 9 on the next page represents the data for 4-year-old Russian children, Figure 10 on the facing page for 6-year-old Russian children, Figure 11 on page 308 for Russian 8-year-olds, and Figure 12 on page 308 for L2 learners. In the same vein as for the rates of correct stem recognition, the figures show that there is a tendency that correct forms were produced more often for high token frequency than for low token frequency items. 


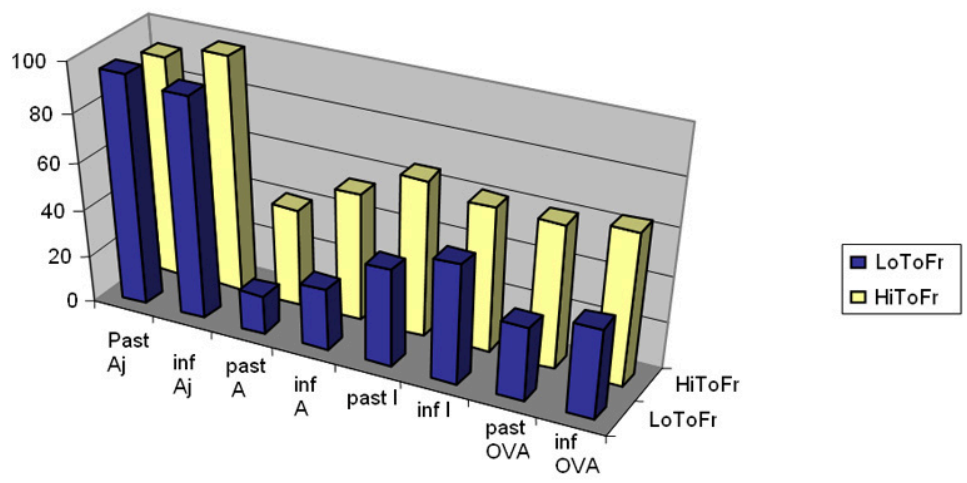

FIGURE 9: Token frequency effects in correctly produced forms for 4-year-olds

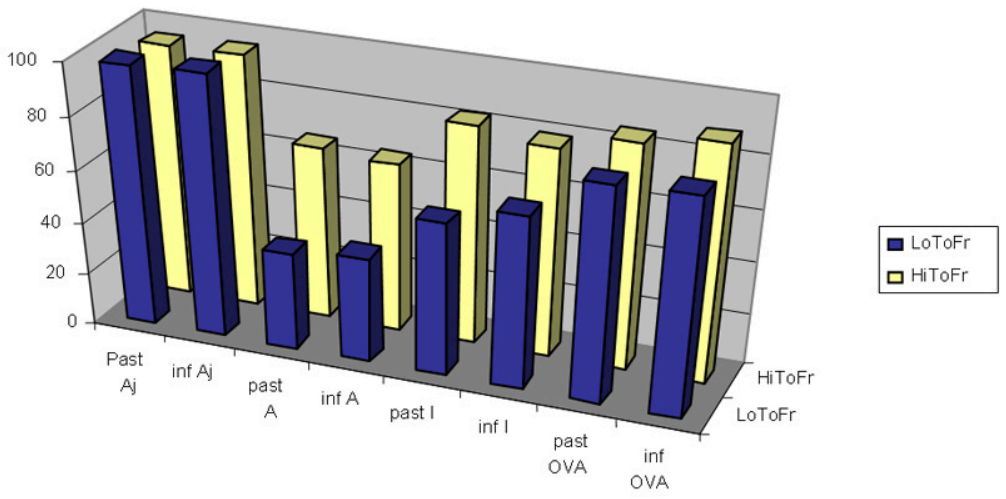

FIGURE 10: Token frequency effects in correctly produced forms for 6-year-olds

When these effects were tested for statistical significance, the statistical analysis has shown that token frequency effects did not reach the level of statistical significance for the -AJ- class in either testing condition for any child groups nor for L2 learners in the past test condition. Token frequency effects were also not statistically significant for the -OVA- class in either test conditions for 6- and 8year-old Russian children. For all other classes the differences in correctly produced forms from high token frequency and low token frequency stimuli were statistically significant.

Here again we observe that token frequency effects are not evident for some classes. Similarly to our observations made for token frequency effects in correct stem recognitions, the effects are not significant for the -AJ- and -OVA-classes for those subject groups, who perform on these classes close to asymptote. However, these results are different for the -I- class: whereas token frequency effects for stem recognitions were not significant for the -I- verbs in groups who per- 


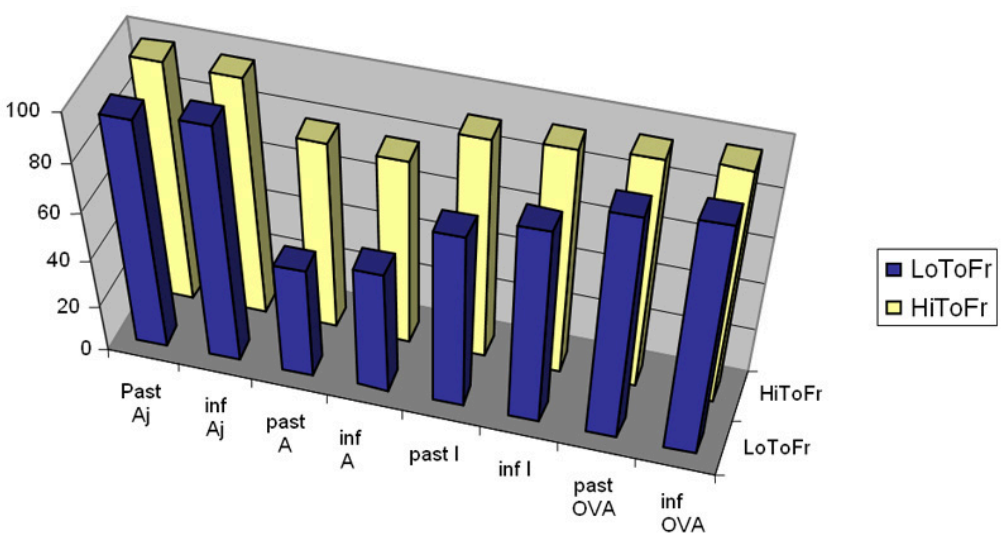

FIGURE 11: Token frequency effects in correctly produced forms for 8-year-olds

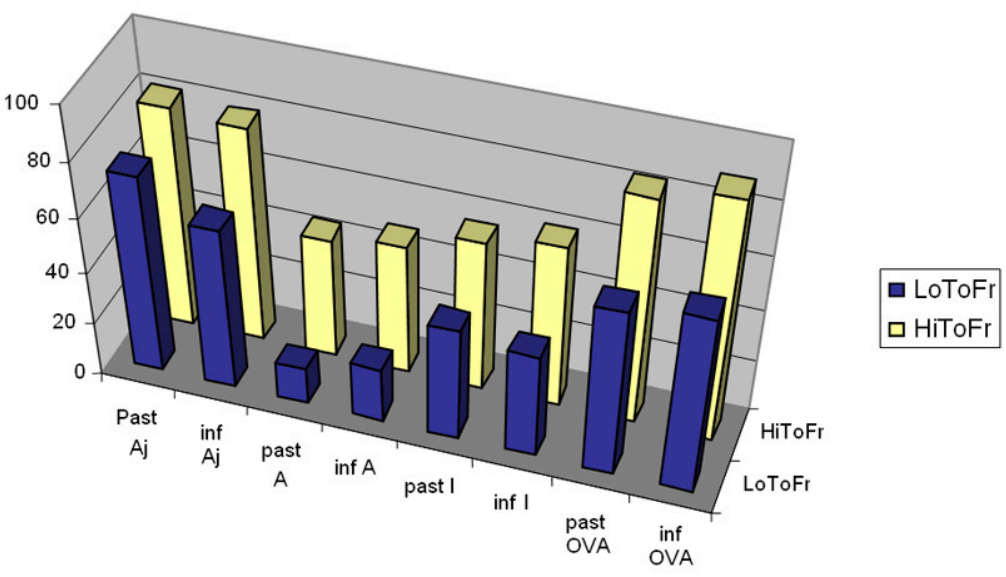

FIGURE 12: Token frequency effects in correctly produced forms for L2 learners

formed over $80 \%$ correct on this class, token frequency effects in correctly produced forms are statistically significant for the -I- class in all subject groups.

This phenomenon can be explained by the influence of morphological complexity. When the performance is estimated in terms of correctly produced forms, morphological complexity comes into play. The -I- and -A- classes are characterised by high morphological complexity (consonant mutations and stress shifts). For this reason, the performance measured in terms of correctly produced forms for these morphologically complex classes is lower than the performance measured in terms of correct stem recognitions, which only registers whether the inflectional class was recognised correctly, but disregards whether the subjects applied all consonant mutations and stress shifts appropriately. 
Thus, these results accord with the assumption expressed above that token frequency influences the acquisition of all inflectional classes, but these effects may be less evident and decrease with a higher proficiency.

\section{[5] DISCUSSION AND CONCLUSION}

In the present study our primary goal was to compare the data on L1 and L2 acquisition of Russian verbal morphology. Studies on L2 morphological processing present an interesting field of research in attempts to shed more light on the question of what role input factors play in morphological processing because L2 learners are potentially exposed to less input than children acquiring this language as an L1. In addition, the L2 classroom learning context differs in several respects from the language environment in which children acquire a language.

Our study has demonstrated that there are some similarities in the acquisition and processing of verbal morphology by Russian children and adult L2 learners. Referring back to different theoretical positions with regard to L2 morphological processing, the fact that L1 and L2 processing of morphology is similar, might support the Shallow Structure Hypothesis (Clahsen \& Felser 2006b,a) and the usagebased approach (Ellis 2002, 2003, 2008).

The similarities that we found regard the role of type and token frequencies in the acquisition of different inflectional patterns and verbs. Throughout our analysis, we have shown that the classes that are characterised by high type frequency in the input are acquired earlier by children and are performed better by L2 learners. The effect of type frequency has also been demonstrated in generalisations the subjects made in response to nonce stimuli, and we observed that morphologically complex patterns which can be called "irregular" were not an exception. This contradicts the main assumption of the Dual Mechanism Account, which assumes that only regular patterns can be generalised. Frequent patterns were easily applied to nonce verbs whenever the stimuli met the requirements of the properties of a particular schema, supporting thus the assumptions made by the usage-based account. The pattern with the highest type frequency was preferred for generalisations by children and L2 learners, however, certain developmental tendencies appeared with age: as children acquired more patterns, they started applying them more frequently to nonce stimuli as well.

Although the L2 learners showed a similar trend to Russian children in their preference of the most frequent inflectional pattern in generalisations, they applied less frequent patterns more often than could have been expected based on our type frequency analysis in the L2 input. This might be a result of formal instruction which manifested itself in a stronger reliance on a clear morphological marker in choosing the -OVA- pattern for generalisation, and also in L2 learners' higher awareness of conjugational patterns with irregularities, and thus higher percentage of use of a rather infrequent -A- pattern for nonce stimuli. 
Our results demonstrate that token frequency influences both rates of correct stem recognitions and correctly produced forms. As was reported by the previous studies (Ellis 1998), the token frequency effects are most influential at the beginning stages of acquisition and diminish with more learning. In accordance with this, we observed that token frequency effects were not significant for those classes and test conditions, in which L2 learners performed close to $100 \%$. Our data have shown that frequency effects exist in both "regular" and "irregular" classes. This particular finding contradicts the Dual Mechanism account of morphological processing predicting frequency effects for irregular patterns but not for regular ones, and supports the predictions made by the Single Mechanism account. This phenomenon was observed in both children and adult L2 learners.

Consequently, a following conclusion may be drawn from our data. In spite of the fact that L2 learners did not match completely any of the child groups in our data, we suggest that at least one of the key underlying principles of morphology acquisition is the same for L1 and L2 context: the process depends on the type frequency. However, for L2 learners other factors may also come into play and we suggest that this might be a result of different language learning environments and different input characteristics. High type frequency of a particular pattern in the L2 input plays an important role in successful acquisition of this pattern, both in terms of correct stem recognition and in its applicability to nonce items. However, low type frequency does not necessarily mean that L2 learners will not acquire the pattern: provided that the pattern has some clear morphological cues and that attention is paid to it in the instruction, it is likely that L2 learners will be able to recognise the pattern, and also apply it to nonce items which meet the requirements on its properties.

The present study demonstrates that the usage-based account of language acquisition is a promising theoretical framework for the field of SLA research. It looks at L1 and L2 acquisition from the same theoretical position and draws lines explaining similarities and differences between them without assuming that different learning principles underlie the L1 and L2 acquisition.

\section{REFERENCES}

Alanen, Riikka. 1995. Input enhancement and rule presentation in second language acquisition. In Richard Schmidt (ed.), Attention and awareness in foreign language learning and teaching, 259-302. Honolulu: University of Hawai'i, Second Language Teaching and Curriculum Center.

Bach Nielsen, Erik. 2003. Grammatika: russisk grammatikk Gyldendals gymnasiale grammatikker. København: Gyldendal.

Berko, Jean. 1958. The child's learning of English morphology. Word 14. 150-177. 
Bjerkeng, Marit \& Tatiana Bräger. 2002. Sosedi 2: begynnerkurs i russisk. Bergen: Fagbokforlaget.

Bjerkeng, Marit, Tatiana Bräger \& Trond Gunnar Nordenstam. 2000. Sosedi 1: begynnerkurs i russisk. Bergen: Fagbokforlaget.

Bybee, Joan. 1995. Regular morphology and the lexicon. Language and Cognitive Processes 10(5). 425-55.

Bybee, Joan \& Paul Hopper. 2001. Frequency and the emergence of linguistic structure (Typological studies in language 45). Amsterdam: John Benjamins.

Bybee, Joan \& Dan Slobin. 1982. Rules and schemas in the development and use of the English past tense. Language 58(2). 265-289.

Celce-Murcia, Marianne. 1991. Grammar pedagogy in second and foreign language teaching. TESOL Quarterly 25(3). 459-480.

Ceytlin, S. N. 2000. Jazyk i rebenok: lingvistika detskoj rechi. (Language and child: linguistics of the child speech). Moskva: Vlados.

Chavronina, S. A. \& A. I. Širočenskaja. 1999. Russian in exercises. Moscow: Russky Yazyk 9 th edn.

Clahsen, Harald. 1997. The representations of participles in the German mental lexicon: Evidence for the dual-mechanism model. Yearbook of morphology 1996. 73-95.

Clahsen, Harald. 2006. Dual-mechanism morphology. In Keith Brown (ed.), Encyclopedia of language and linguistics, vol. 4, 1-5. Elsevier.

Clahsen, Harald \& Claudia Felser. 2006a. Continuity and shallow structures in language processing. Applied Psycholinguistics 27(1). 107-126.

Clahsen, Harald \& Claudia Felser. 2006b. Grammatical processing in language learners. Applied Psycholinguistics 27(1). 3-42.

Cornyn, William S. 1948. On the classification of Russian verbs. Language 24(1). 64-75.

DeKeyser, Robert M. 1997. Beyond explicit rule learning. Studies in Second Language Acquisition 19(2). 195-221.

Dörnyei, Zoltán. 2005. The psychology of the language learner: individual differences in second language acquisition. Mahwah, NJ: Lawrence Erlbaum Associates. Zoltan Dörnyeifig. 
Dörnyei, Zoltán \& Peter Skehan. 2002. Individual differences in second language acquisition. Amsterdam: John Benjamins.

Doughty, Catherine \& Jessica Williams. 1998. Pedagogical choices in focus on form. In Catherine Doughty \& Jessica Williams (eds.), Focus on form in classroom second language acquisition, 197-261. Cambridge: Cambridge University Press.

Eddington, David. 2002. Dissociation in Italian conjugations: a single-route account. Brain and Language 81(1-3). 291-302.

Ellis, Nick C. (ed.). 1994. Implicit and explicit learning of languages. San Diego: Academic Press.

Ellis, Nick C. 1998. Rules or associations in the acquisition of morphology? The frequency by regularity interaction in human and PDP learning of morphosyntax. Language and Cognitive Processes 13(2). 307-336.

Ellis, Nick C. 2002. Frequency effects in language processing: A review with implications for theories of implicit and explicit language acquisition. Studies in Second Language Acquisition 24(2). 143-188.

Ellis, Nick C. 2003. Constructions, chunking, and connectionism: the emergence of second language structure. In Catherine Doughty \& Michael H. Long (eds.), The handbook of second language acquisition, 63-103. Oxford: Blackwell Publishing.

Ellis, Nick C. 2005. At the interface: Dynamic interactions of explicit and implicit language knowledge. Studies in second language acquisition 27(2). 305-352.

Ellis, Nick C. 2008. Usage-based and form-focused language acquisition. In Peter Robinson \& Nick C. Ellis (eds.), Handbook of cognitive linguistics and second language acquisition, 372-405. New York - London: Routledge.

Ellis, Rod. 1990. Instructed second language acquisition: learning in the classroom Applied language studies. Oxford: Blackwell.

Eubank, Lynn (ed.). 1991. Point counterpoint: universal grammar in the second language (Language acquisition \& language disorders 3). Amsterdam: John Benjamins.

Flynn, Suzanne. 1996. A parameter-setting approach to SLA. In William C. Ritchie \& Tej K. Bhatia (eds.), The handbook of second language acquisition, 121-158. San Diego: Academic Press.

Gagarina, Natalia. 2002. Productivity of the verbal inflectional classes (the case of Russian). In Katarzyna Dziubalska-Kolaczuk \& Jarek Weckwerth (eds.), Future challenges for natural linguistics (Lincom studies in theoretical linguistics 30), 153-164. Wien: Lincom Europa. 
Gagarina, Natalia. 2003. The early verb development and demarcation of stages in three Russian-speaking children. In Dagmar Bittner, Wolfgang U. Dressler, Marianne Kilani-Schoch \& Peter Jordens (eds.), Development of verb inflection in first language acquisition: a cross-linguistic perspective (Studies on Language Acquisition 21), 131-169. Berlin, New York: Mouton de Gruyter.

Gass, Susan. 1996. Second language acquisition and linguistic theory: The role of language transfer. In William S. Ritchie \& Tej Bhatia (eds.), Handbook of second language acquisition, 317-345. San Diego, Calif.: Academic Press.

Gathercole, Virginia C. 2007. Miami and North Wales, so far and yet so near: Constructivist account of morpho-syntactic development in bilingual children. International Journal of Bilingual Education and Bilingualism 10(3). 224-247.

Gilmore, Alex. 2007. Authentic materials and authenticity in foreign language learning. Language Teaching 40.97-118.

Goldberg, Adele E. 2006. Constructions at work: The nature of generalization in language. Oxford: Oxford University Press.

Gor, Kira. 2004. The rules and probabilities model of native and second language morphological processing. In L. Verbitskaya \& Tatiana Chernigovskaya (eds.), Teoreticheskie problemy jazykoznanija. sbornik statej k 140-letiju kafedry obschego jazykoznanija (Theoretical problems in linguistics. Papers dedicated to 140th anniversary of the Department of General Linguistics, St. Petersburg State University), 51-75. St. Petersburg: Philological Faculty of St. Petersburg State University Press.

Gor, Kira. 2007. Experimental study of first and second language morphological processing. In Monica Gonzalez-Marques, Irene Mittelberg, Seana Coulson \& Michael J. Spivey (eds.), Methods in cognitive linguistics, 367-398. Amsterdam: John Benjamins.

Gor, Kira \& Tatiana Chernigovskaya. 2004. Generation of complex verbal morphology in first and second language acquisition: Evidence from Russian. Nordlyd. Tromsø University Working Papers on Language and Linguistics 31(6). 819-833. http://www.ub.uit.no/munin/nordlyd/viewissue.php?id=6.

Gor, Kira \& Tatiana Chernigovskaya. 2005. Formal instruction and the acquisition of verbal morphology. In Alex Housen \& Michel Pierrard (eds.), Investigations in instructed second language acquisition, 103-139. New York: Mouton De Gruyter.

Hahne, Anja, Jutta L. Mueller \& Harald Clahsen. 2006. Morphological processing in a second language: Behavioral and event-related brain potential evidence for storage and decomposition. Journal of cognitive neuroscience 18(1). 121-134. 
Hyltenstam, Kenneth. 1992. Non-native features of near-native speakers. On the ultimate attainment of childhood L2 learners. In R. Harris (ed.), Cognitive processing in bilinguals, 351-368. Amsterdam: Elsevier Science Publishers.

Hyltenstam, Kenneth \& Niclas Abrahamsson. 2000. Who can become native-like in a second language? All, some, or none? On the maturational constraints controversy in second language acquisition. Studia linguistica 54(2). 150-166.

Jakobson, Roman. 1948. Russian conjugation. Word 4(3). 155-167.

Kemmer, Suzanne \& Michael Barlow (eds.). 2000. Usage-based models of language. Stanford, Calif.: CSLI Publications.

Kiebzak-Mandera, Dorota. 2000. Formation of the verb system in Russian children. Psychology of Language and Communication 4.27-46.

Kiebzak-Mandera, Dorota, Magdalena Smoczynska \& Ekaterina Protassova. 1997. Acquisition of Russian verb morphology: The early stages. In Wolfgang $U$. Dressler (ed.), Studies in pre- and protomorphology, 101-114. Wien: Verlag der Österreichischen Akademie der Wissenschaften.

Langacker, Ronald W. 1987. Foundations of cognitive grammar. Stanford, Calif.: Stanford University Press.

Langacker, Ronald W. 2000. A dynamic usage-based model. In Michael Barlow \& Suzanne Kemmer (eds.), Usage-based models of language, 1-63. Stanford: CSLI Publications.

Long, Michael. 1991. Focus on form: A design feature in language teaching methodology. In Kees De Bot, Claire Kramsch \& Ralph B. Ginsberg (eds.), Foreign language research in cross-cultural perspective (Studies in bilingualism 2), 39-52. Amsterdam: John Benjamins.

Long, Michael H. \& Peter Robinson. 1998. Focus on form. theory, research and practice. In Catherine Doughty \& Jessica Williams (eds.), Focus on form in classroom second language acquisition, 15-41. Cambridge: Cambridge University Press.

MacWhinney, Brian. 1997. Implicit and explicit processes. Studies in Second Language Acquisition 19(2). 277-281.

MacWhinney, Brian \& Jared Leinbach. 1991. Implementations are not conceptualizations: revising the verb learning model. Cognition 40(1-2). 121-157.

Marchman, Virginia \& Elizabeth Bates. 1994. Continuity in lexical and morphological development: a test of the critical mass hypothesis. Journal of Child Language 21. 399-366. 
Marcus, Gary. 1995. The acquisition of the English past tense in children and multilayered connectionist networks. Cognition 56(3). 271-279.

Marcus, Gary, Ursula Brinkmann, Harald Clahsen, Richard Wiese \& Steven Pinker. 1995. German inflection: the exception that proves the rule. Cognitive Psychology 29(3). 189-256.

Marcus, Gary, Steven Pinker, Michael Ullman, Michelle Hollander, T. J. Rosen \& Fei Xu. 1992. Overregularization in language acquisition. Monographs of the Society for Research in Child Development 57(4). i+iii+v+vi+1-178.

Marslen-Wilson, William \& Lorraine K. Tyler. 1998. Rules, representations, and the English past tense. Trends in Cognitive Sciences 2(11). 428-435.

Marslen-Wilson, William \& Lorraine K. Tyler. 2005. The lexicon, grammar, and the past tense: Dissociation revisited. In Michael Tomasello \& Dan Slobin (eds.), Beyond nature-nurture: Essays in honor of elizabeth bates, 263-280. Mahwah, NJ: Lawrence Erlbaum.

Masgoret, Anne-Marie \& Robert C. Gardner. 2003. Attitudes, motivation, and second language learning: a meta-analysis of studies conducted by Gardner and associates. Language Learning 53(1). 123-63.

Mathiassen, Terje. 1996. Russisk grammatikk. Oslo: Universitetsforlaget 2nd edn.

McClelland, James L. \& Karalyn Patterson. 2002a. Rules or connections in pasttense inflections: What does the evidence rule out? Trends in Cognitive Sciences 6(11). 265-272.

McClelland, James L. \& Karalyn Patterson. 2002b. 'Words Or Rules' cannot exploit the regularity in exceptions (reply to Pinker and Ullman). Trends in Cognitive Sciences 6(11). 464-465.

Nesset, Tore. 1996. Russian conjugation revisited: a cognitive approach to aspects of russian verb inflection. Oslo: University of Oslo, Faculty of Arts.

Nesset, Tore. 2004. Truncation without truncation? Poljarnyj Vestnik 7. 56-73.

Nesset, Tore. 2008. Abstract phonology in a concrete model: Cognitive linguistics and the morphology-phonology interface. Berlin: Mouton de Gruyter.

Nizegorodcew, Anna. 2007. Input for instructed L2 learners. Clevedon: Multilingual Matters.

Norris, John M. \& Lourdes Ortega. 2000. Effectiveness of L2 instruction: a research synthesis and quantitative meta-analysis. Language Learning 50. 417-528. 
Norris, John M. \& Lourdes Ortega. 2001. Does type of instruction make a difference? Substantive findings from a meta-analytic review. Language Learning 51(S1). 157-213.

Pinker, Steven. 1999. Words and rules: the ingredients of language. London: Weidenfeld \& Nicolson.

Pinker, Steven. 2001. Four decades of rules and associations, or whatever happened to the past tense debate? In E. Dupoux (ed.), Language, the brain, and cognitive development: Papers in honor of Jacques Mehler, 157-179. Cambridge, MA: MIT Press.

Pinker, Steven \& Alan Prince. 1988. On language and connectionism: analysis of a parallel distributed processing model of language acquisition. Cognition 28. 73-193.

Pinker, Steven \& Michael Ullman. 2002. The past and future of the past tense. Trends in Cognitive Sciences 6(11). 456-463.

Plunkett, Kim \& Virginia Marchman. 1991. U-shaped learning and frequency effects in a multi-layered perceptron: implications for child language acquisition. Cognition 38. 43-102.

Plunkett, Kim \& Virginia Marchman. 1993. From rote learning to system building: acquiring verb morphology in children and connectionist nets. Cognition 48 . 21-69.

Plunkett, Kim \& Virginia Marchman. 1996. Learning from a connectionist model of the English past tense. Cognition 61. 299-308.

Prasada, Sandeep \& Steven Pinker. 1993. Generalization of regular and irregular morphological patterns. Language and Cognitive Processes 8(1). 1-56.

Protassova, Ekaterina. 1997. Transition from babbling to word structure. Papers and Studies in Contrastive Linguistics 33. 153-158.

Robinson, Peter. 1996. Consciousness, rules, and instructed second language acquisition (Theoretical Studies in Second Language Acquisition 7). New York: Peter Lang.

Robinson, Peter. 2002. Individual differences and instructed language learning (Language learning and language teaching 2). Amsterdam: John Benjamins.

Robinson, Peter \& Nick C. Ellis (eds.). 2008. Handbook of cognitive linguistics and second language acquisition. New York, London: Routledge. 
Rumelhart, David E. \& James L. McClelland. 1986. On learning the past tenses of English verbs. In David E. Rumelhart \& James L. McClelland (eds.), Parallel distributed processing: Explorations in the microstructure of cognition, vol. II, 216-271.

Scatton, Ernest A. 1984. Two stems or not two stems, is that the question? In Sophia Lubensky \& Donald K. Jarvis (eds.), Teaching, learning, acquiring Russian, 213-227. Columbus: Slavica.

Schwartz, Bonnie D. 1992. Testing between UG-based and problem-solving models of L2A: Developmental sequence data. Language Acquisition 2. 1-19.

Sharwood Smith, M. 1993. Input enhancement in instructed SLA. Studies in Second Language Acquisition 15(2). 165-179.

Singleton, David. 2003. Age and second language acquisition. Annual review of applied linguistics $21.77-89$.

Slioussar, Natalja A. 2003. Psicholingvističeskoe issledovanie struktury mental'nogo leksikona na materiale russkih glagolov. (Psycholinguistic study of the mental lexicon structure based on the Russian verb investigation). St.Petersburg SPbGU MA thesis.

Spada, Nina. 1997. Form-focused instruction and second language acquisition: A review of classroom and laboratory research. Language Teaching 30. 73-87.

Tomasello, Michael. 2003. Constructing a language: a usage-based theory of language acquisition. Cambridge, Mass.: Harvard University Press.

Townsend, Charles E. 1975. Russian word-formation. Columbus, Ohio: Slavica Publishers corr. repr. edn. By Charles E. Townsend.

Ullman, Michael. 1997. A neural dissociation within language: Evidence that the mental dictionary is part of declarative memory, and that grammatical rules are processed by the procedural system. Journal of Cognitive Neuroscience 9(2). 266-276.

Ullman, Michael. 1999. Acceptability ratings of regular and irregular past-tense forms: Evidence for a dual-system model of language from word frequency and phonological neighbourhood effects. Language and Cognitive Processes 14(1). 47-67.

Ullman, Michael. 2001a. The declarative/procedural model of lexicon and grammar. Journal of Psycholinguistic Research 30(1). 37-69.

Ullman, Michael. 2001b. The neural basis of lexicon and grammar in first and second language: The declarative/procedural model. Bilingualism: Language and Cognition 4(1). 105-122. 
Ullman, Michael. 2001c. A neurocognitive perspective on language: The declarative/procedural model. Nature reviews. Neuroscience 2(10). 717-726.

Ullman, Michael. 2004. Contributions of memory circuits to language: The declarative/procedural model. Cognition 92(1-2). 231-270.

Ullman, Michael. 2006. The declarative/procedural model and the shallow structure hypothesis. (commentary on Clahsen \& Felser). Applied Psycholinguistics 27(1). 97-105.

Švedova, N. Ju. 1980. Russkaja grammatika. Moskva: Nauka.

White, Joanna. 1998. Getting the learners' attention. A typographical input enhancement study. In Catherine Doughty \& Jessica Williams (eds.), Focus on form in classroom second language acquisition, 85-113. Cambridge: Cambridge University Press.

White, Lydia. 1989. Universal grammar and second language acquisition (Language acquisition \& language disorders 1). Amsterdam: Benjamins.

White, Lydia. 2003. On the nature of interlanguage representation: Universal Grammar in the second language. In Catherine Doughty \& M. Long (eds.), Handbook of second language acquisition, 19-42. Oxford: Blackwell.

Zaliznjak, A. A. 1980. Grammaticeskij slovar' russkogojazyka: slovoizmenenie. Moskva: Russkij jazyk. A. A. Zaliznjak.

Zasorina, L. N. \& V. A. Agraev. 1977. Chastotnyj slovar' russkogo jazyka : okolo 40000 slov (Russian frequency dictionary: about 40000 words). Moskva: Russkij jazyk.

AUTHOR CONTACT INFORMATION

Elena Tkachenko

Department of Linguistics and Scandinavian Studies

University of Oslo

Norway

elena.tkachenko@lui.hio.no

Tatiana Chernigovskaya

Department of General Linguistics, Philological Faculty

St. Petersburg State University

Russia

tatiana.chernigovskaya@gmail.com 